\title{
On the Behaviour of Sulphide and Selenide Inclusions \\ Formed in Steel Containing Chromium and Molybdenum*
}

\author{
By Toru Araki**, Haruhiko Hirai***, Yukio Matsushita** \\ and Töru Karasudani ${ }^{* * * *}$
}

\section{Synopsis}

The effects of varied elements on the behaviour of sulphides and relative nonmetallic inclusions in a resulphurized steel were morphologically investigated using small scale ingots, whose compositions were based on $0.1 \% \mathrm{C}$ killed steels with and without $\mathrm{Cr}$ and/or Mo.

At the same time the effects of deoxidizing conditions before solidification were studied, e.g., of various grades of $\mathrm{Al}$-killed conditions and vacuum melting process.

The morphological observation of sulphides etc. was mainly carried out with the microscope; in addition the results were certified by the qualification with the electron probe X-ray microanalyser and the identification of electrolyzed residues of the steels by $X$-ray diffraction method.

The results obtained were as follows:

(1) In the case of low carbon steels, increased sulphur content and increased carbon content affect the formation behaviour of sulphide on the primary grain and boundaries. The increased molybdenum content up to $2 \%$ has a tendency to change the $\mathrm{FeS}$ phase into $\mathrm{MnS}$ when precipitated in primary crystals, although there exists no increased concentration of molybdenum in the sulphides.

(2) In the case of $\mathrm{Cr}$-containing steels, the morphological aspects of sulphides and selenides were notably affected by the deoxidizing conditions before solidified. Those phenomena can presumably be interpreted on the basis of the relation between the natures of deoxidation products and the nucleation of sulphides.

(3) Many kinds of sulphides and selenide inclusions occurring in various conditions were analyzed qualitatively with respect to the effect of molybdenum and also to the hot plasticity. A relation was observed among the compositions and crystal structures of sulphides and their plasticities also in accord with the molybdenum contents.

\section{Introduction}

Generally speaking, sulphide inclusions in steel deteriorate properties of steel, causing red-shortness and hardening - crack etc., but in the other hand, as the sulphide involved in steel weakens its material strength around the shear plane at the cool point on cutting and acts as a internal lubricant in flowing; those inclusions are qualified as to fabour the machinability.

In the case of the steel materials of which machining work has technologically a significant role, so-called free cutting steels containing 0.1 to 0.3 pct. sulphur are widely utilized. The sulphides formed in these steels in general cases are manganese sulphides, of which, depending on different history of melting and ingotmaking process, the spherical inclusions are formed with single phase or duplex phase involving $\mathrm{MnS}$, $\mathrm{FeS}, \mathrm{MnO}, \mathrm{SiO}_{2}, \mathrm{Al}_{2} \mathrm{O}_{3}$, and used to give various aspects of machinability to each steel. ${ }^{1,2)}$ Sulphides CrS, VS, ZrS and NbS but for the above stated sul- phides are formed in the alloy steels with added special elements. ${ }^{6), 8)}$ Morphology and physical properties of the sulphides are to depend largely on the composition of elements and melting condition.

In former days, existence of molybdenum-sulphide in containing steels has once been believed, but nowadays it is denied from the results of the modern investigations, i.e. single molybdenum sulphide cannot be identified in ordinary composition range of steels.

There are many studies on sulphides which will be produced in iron and steel with some added special elements, viz, in ternary system (Fe-X-S) or also quadri-(Fe-Mn-X-S) alloys, ${ }^{31,4)}$ and many equilibrium diagrams are given for sulphides based on pure iron alloy system.

The interactions between oxygen, carbon and other elements are not to be said as wholly revealed in commercially melted steels, but most of studies remain in a stage of fundamental research work.

There are so many unknown matters involved in the obtained informations of phenomena occurring in commercial steel ingots.

The authors studied the influence of various elements in low carbon chromium steels on the precipitating condition of sulphide, which shall affect the constitution and the morphology of sulphides, and also investigated melting conditions, above all the degree of deoxidation and the sort of deoxidizer, markedly influenced the constitution of sulphide (or selenide) inclusions which precipitate during solidification of ingot and the deformation behaviour in forging work.

The aim of this experiment lies in getting some metallurgical knowledges which shall be advantageous for manufacturing and engineering practice of some free-cutting steels.

\section{Preliminary Experiment and Results}

As the first step of the investigation resulphurized low carbon steel samples were examined by microscopic testing and X-ray study of the electrolytic residue of them.

The samples were melted by Tamman furnace in $500 \mathrm{~g}$ magnesia crucible and solidified outside (Table 1). The small ingots were cut and offered to identification of inclusions and morphological study etc.

Observations with optical microscope and Cameca's

* This article is in reference to the lecture delivered before the 66th Grand Lecture Meeting of The Iron and Steel Institute of Japan in October 1963 in Nagoya. Japanese text was received on April 2, 1964 and printed in "Tetsu-to-Hagané", 50 (1964), 2310-2324 with some more details.

** Prof.-Dr. Eng., University of Tokyo.

*** National Research Institute for Metals.

**** Sanyo Special Steel Co., Ltd. 
Table 1. Chemical composition of low carbon steel samples (\%)

\begin{tabular}{c|c|c|c|c|c|c}
\hline Steel & $\mathrm{C}$ & $\mathrm{Si}$ & $\mathrm{Mn}$ & $\mathrm{S}$ & $\mathrm{Mo}$ & $\mathrm{O}$ \\
\hline$T_{1}$ & 0.13 & 0.38 & 0.62 & 0.28 & - & 0.006 \\
\hline$T_{2}$ & 0.07 & 0.40 & 0.50 & 0.29 & 0.39 & 0.010 \\
\hline$T_{3}$ & 0.07 & 0.40 & 0.53 & 0.27 & 1.94 & 0.012 \\
\hline$T_{4}$ & 0.06 & 0.39 & 0.58 & 0.40 & 0.48 & 0.007 \\
\hline$T_{5}$ & 0.04 & 0.39 & 0.58 & 0.27 & 1.95 & 0.011 \\
\hline$T_{6}$ & 0.36 & 0.41 & 0.58 & 0.26 & 0.46 & 0.004 \\
\hline
\end{tabular}

electron probe microanalyser revealed, that base steel $T_{1}$ had both $\mathrm{FeS}$ and $\mathrm{MnS}$ inclusions of nearly equal amount and samples with increased molybdenum and /or sulphur content seemed to change the ratio $\mathrm{FeS} /$ $\mathrm{MnS}$. Steel $\mathcal{T}_{4}$, which contains higher sulphur $(0.4 \%)$ showed much amount of coalesced spherical FeS inclusions but very few film like sulphide (network) was found despite low manganese by sulphur ratio; whereas higher carbon sample $T_{6}$ showed perfect FeS network.

X-ray diffraction study of the anod slime of each steel proved semi-quantitatively the same identification of included sulphide species as the above stated observation.

Table 2 shows the occurrence of $\mathrm{MnS}$ and $\mathrm{FeS}$ inclusions both in grains and on grain boundaries by point counting method.

Table 2. Occurrence of sulphides (FeS, MnS) in grains and grain boundaries

\begin{tabular}{c|c|c|c|c|c}
\multirow{2}{*}{ Steel } & \multicolumn{3}{|c|}{ (In grains)* } & (On grain boundaries)* \\
\cline { 2 - 6 } & Mo\% & MnS & FeS & MnS & FeS \\
\hline$T_{1}$ & - & 0.13 & 0.09 & 0.17 & 0.01 \\
\hline$T_{2}$ & 0.39 & 0.32 & 0.11 & 0.14 & 0.06 \\
\hline$T_{3}$ & 1.94 & 0.18 & 0.02 & 0.16 & 0.02 \\
\hline$T_{5}$ & 1.95 & 0.19 & 0.01 & 0.17 & 0.01 \\
\hline$T_{6}$ & $(\mathrm{C}=0.36)$ & 0.17 & 0.07 & 0.0 & 0.25 \\
\hline
\end{tabular}

* Note: area distribution (\%) by point counting.

Through this experiment, no molybdenum sulphide or no concentrating phenomenon of molybdenum into sulphide was observed; this fact means no possibility of molybdenum sulphide inclusions in commercial free-cutting steels. A new finding was, judging from the result of Table 2 and the X-ray determination of residues, that added molybdenum in low carbon steels would influence the precipitating condition of $\mathrm{FeS}$ and change FeS into MnS-solid solution. This phenomenon may be interpreted from a viewpoint of chemical interaction of molybdenum with sulphur in molten steel bath and also partly affected nucleating condition of iron sulphide vs. manganese sulphide at the formation stage of primary grain of steel.

The higher sulphur specimen $T_{4}$ had relatively low oxygen content despite its low carbon (0.06) percentage, that supposingly resulted from the reaction:

$$
\underline{\mathrm{S}}+2 \underline{\mathrm{O}} \rightarrow \mathrm{SO}_{2}(\mathrm{~g})
$$

Fig. 1 shows the $[\% \mathrm{C}]-[\% \mathrm{O}]$ relationship in all specimens, where mark $\bullet$ means downward deviation of oxygen from carbon equilibrium. In view of this series samples increased carbon content appeared to accelerate network formation on grain boundary.

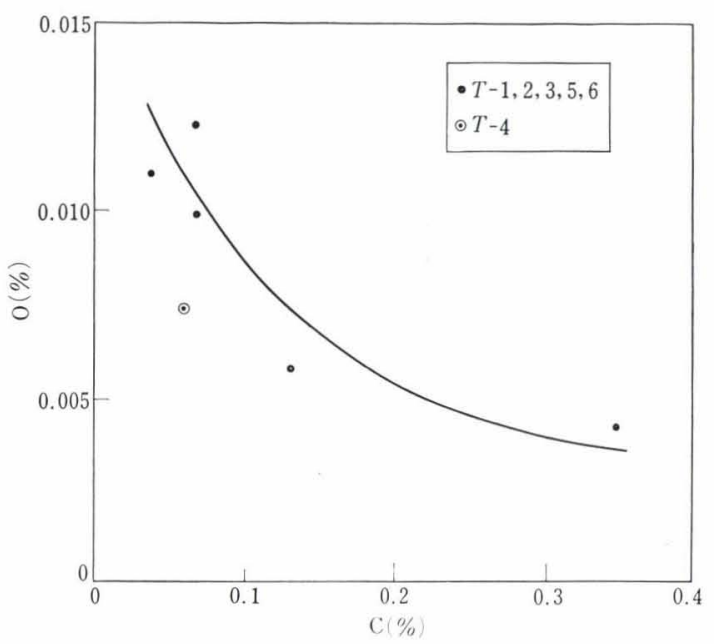

Fig. 1. Relation between carbon and oxygen in $T_{1 \sim 6}$ samples

\section{Experiments on Free-Cutting Nonmetallic Inclusions Formed in Higher Cr-Steel}

The authors have written in the preceding section the behaviours of sulphide inclusions formed in carbon steel, but the behaviours in the case of higher chromium steel such as stainless steel and tool steel might be quite different from them.

Some investigations were reported on pure alloy system of Fe-Mn-Cr-S. ${ }^{6,7)}$ On sulphide inclusions formed in higher $\mathrm{Cr}$-steels for practical use, for example free-cutting stainless steels, virtually no research work has reported on influences of melting conditions and metallurgical effects of $\mathrm{Mo}$ or $\mathrm{Zr}$ in steel. In this experiment four groups of low carbon higher Cr-steel which represent basic forms of stainless steel and higher tool steel, were melted as follows,

$A$ - open melting (higher oxygen content and Al-killed)

$A^{\prime}$ - open melting (appropriately killed with $\mathrm{Al}$ )

$V^{\circ}$ - vacuum melting (Si-Mn deoxidized, iron oxide added)

$V$ — vacuum melting (Si-Mn deoxidized, no oxide added)

Of these groups, some tests and identification study were carried out on form, constitution, size and distribution of free-cutting nonmetallic inclusions in steel formed by additives such as S, Se and Zr and deformed inclusions by forging.

\section{Specimens}

\section{Melting of Samples Used}

Samples used were melted in high frequency induction type both air and vacuum-melting furnaces for $10 \mathrm{~kg}$ ingot. Chemical composition of samples, as shown in Tables 3 and 4, can be divided into four 
groups such as $A, A^{\prime}, V^{\circ}$ and $V$.

Rolled bars from commercial steel and Swedish pig iron (recarburizing material) were used for melting raw material of $A-, A_{\mathrm{Se}^{-}}, V^{\circ}$ and $V_{\mathrm{Se}}^{\circ}$-group. Each element, i.e. $\mathrm{Cr}, \mathrm{Mo}, \mathrm{Zr}$ or Se, was added in pure metallic state.

Molten steel was deoxidized by $\mathrm{Mn}-\mathrm{Si}-(\mathrm{Al})$ after addition of resulphurizer pyrite $\left(\mathrm{FeS}_{2}\right)$ at $1,550^{\circ} \mathrm{C}$ (metallic $\mathrm{Zr}$ and $\mathrm{Se}$ were added after deoxidation). As vacuum melting was efficiently accomplished, pyrites $\left(\mathrm{FeS}_{2}\right)$, scale of mild steel $\left(\mathrm{Fe}_{3} \mathrm{O}_{4}\right)$ and Selenium were added one after another controlling components in molten steel bath under enclosed Aratmosphere. Then, molten steel of $7 \mathrm{~kg}$ ingot was cast into cast iron mold at about $1,500^{\circ} \mathrm{C}$.

Al-deoxidation (Al : $0.5 \mathrm{~g} / \mathrm{kg}$ ) was made in each group of $A, A^{\prime}$ and $A_{\mathrm{Se}}$, but in the following groups $V, V^{\circ}$ and $V_{\mathrm{Se}}^{\circ}$, finishing deoxidation was carried out by $\mathrm{Mn}-\mathrm{Si}$ deoxidizer. Samples of $A$-group showed high oxidizing degree because of including oxidized materials but those of $A^{\prime}$-group showed lower oxidizing degree and suitable Al-deoxidation practice. The oxygen content in each sample of $V^{\circ}$-group is higher than that in $V$-group, owing to the addition of $\mathrm{Fe}_{3} \mathrm{O}_{4}$ (oxygen: $0.010 \%$ ). The yields of oxygen and sulphur in steel were not so high, for a part of the oxygen content added into molten steel reacted with sulphur in molten steel, which should have evolved gas phase.

\section{Forging Procedure of Samples}

In order to compare the elongation degree of sulphide inclusions in each group, two stages of forging with the ratio of four and sixteen were carried out in the bottom part at $1,150^{\circ} \sim 950^{\circ} \mathrm{C}$.

\section{Experimental Results}

\section{Macrostructure Tests of Ingots}

The examination of segregation mode of sulphide inclusions at the middle part of ingot was done by sulphur-print method, but no remarkable segregation was observed.

Table 3. Aimed and resulted analytical composition of sulphide containing samples (\%)

\begin{tabular}{|c|c|c|c|c|c|c|c|c|c|c|}
\hline Condition & $\begin{array}{l}\text { Element } \\
\text { Group } \\
\end{array}$ & $\mathrm{C}$ & $\mathrm{Si}$ & Mn & $\mathrm{Cr}$ & Mo & $\mathrm{S}$ & $\mathrm{A} 1$ & $\mathrm{Zr}$ & $\mathrm{O}$ \\
\hline \multirow{7}{*}{ Air melting } & $A-1$ & $\begin{array}{l}(0.11) \\
0.121\end{array}$ & $\begin{array}{c}(0.40) \\
0.39\end{array}$ & $\begin{array}{c}(0.65) \\
0.43\end{array}$ & $\begin{array}{l}(10.0) \\
10.40\end{array}$ & $\begin{array}{r}0.3) \\
0.41\end{array}$ & $\begin{array}{l}(0.33) \\
0.344\end{array}$ & $\begin{array}{l}(0.02) \\
0.015\end{array}$ & - & 0.016 \\
\hline & $A-2$ & (. & $(0 ., 15)$ & $(0.40)$ & 10.67 & $\begin{array}{r}(3.0) \\
2.88\end{array}$ & (., & (.,ö) & - & - \\
\hline & $A-3$ & (...') & $\left({ }_{0.19}\right)$ & $\left(0.45^{\prime}\right)$ & $\begin{array}{r}(5.0) \\
7.58\end{array}$ & $\begin{array}{r}(10.0) \\
9.55\end{array}$ & $\left(\begin{array}{l}(., 3) \\
0.312\end{array}\right.$ & $\left({ }_{0.0 ̈}\right)$ & - & - \\
\hline & $A-4$ & (...') & $\left.\left(0 .{ }^{\prime}\right)^{\prime}\right)$ & $(0.69)$ & $\begin{array}{l}(10.0) \\
10.67\end{array}$ & $\begin{array}{c}0.3) \\
0.31\end{array}$ & ( 0.380$)$ & (o.,.') & $\begin{array}{c}(0.15) \\
0.15\end{array}$ & 0.012 \\
\hline & $A^{\prime}-1$ & (...') & $(0 ., 44)$ & $(0.56)$ & (12.,52) & $\begin{array}{r}(0.3) \\
0.30\end{array}$ & $(0.354$ & 0.024 & - & 0.006 \\
\hline & $A^{\prime}-2$ & 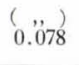 & $\left({ }_{0.40}^{\prime \prime}\right)$ & $(0 ., 53)$ & $(12 ., 46)$ & $\begin{array}{l}(3.0) \\
2.97\end{array}$ & $\left(\begin{array}{l}(, 336) \\
0.336\end{array}\right.$ & (.,.') & - & - \\
\hline & $A^{\prime}-3$ & ( 0.071 & $\left({ }_{0.40}^{\prime \prime}\right)$ & $(0 ., 51)$ & $\begin{array}{r}5.0) \\
5.51\end{array}$ & $\begin{array}{l}(10.0) \\
10.40\end{array}$ & $\left(\begin{array}{l}(, 3) \\
0.322\end{array}\right.$ & $\left(\begin{array}{l}(, 0) \\
0.011\end{array}\right.$ & - & - \\
\hline \multirow{6}{*}{ Vacuum melting } & $V^{\circ}-1$ & (.,.̈) & $\begin{array}{c}(0.35) \\
0.53\end{array}$ & $(0.42)$ & $\begin{array}{l}(10.0) \\
10.00\end{array}$ & $\begin{array}{c}(0.3) \\
0.38\end{array}$ & ( 0.202 & - & - & 0.003 \\
\hline & $V^{\circ}-2$ & (.,ö) & $\left({ }_{0.07}\right)$ & $(0 ., 44)$ & $\begin{array}{l}(10.0) \\
10.07\end{array}$ & $\begin{array}{r}(3.0) \\
3.05\end{array}$ & $\left(\begin{array}{c}(, 2 \\
0.218\end{array}\right.$ & - & - & - \\
\hline & $V^{\circ}-3$ & $(0.080)$ & $(0 ., 50)$ & $(0.41)$ & $\begin{array}{r}5.0) \\
7.13\end{array}$ & $\begin{array}{r}(10.0) \\
9.54\end{array}$ & $(0.390)$ & - & - & - \\
\hline & $V-1$ & (..0̈) & $(0,43)$ & $(0 ., 43)$ & $\begin{array}{r}(10.0) \\
10.00\end{array}$ & $\begin{array}{c}(0.3) \\
0.31\end{array}$ & $(0.281)$ & - & - & 0.002 \\
\hline & $V-2$ & $(0.054)$ & $\left(\begin{array}{c}(, 30) \\
0.40\end{array}\right.$ & $(0.40)$ & $(10 ., 11$ & $\begin{array}{r}(3.0) \\
3.18\end{array}$ & $\left(\begin{array}{c}(, 29) \\
0.294\end{array}\right.$ & - & - & - \\
\hline & $V-3$ & (o.0̈) & $\left(\begin{array}{c}(,, 4) \\
0.42\end{array}\right.$ & $(0.39)$ & $\begin{array}{r}(5.0) \\
7.13\end{array}$ & $\begin{array}{l}(10.0) \\
10.20\end{array}$ & (o.,202) & - & - & - \\
\hline
\end{tabular}

Note: ( ) =Aimed composition.

Table 4. Aimed and resulted analytical composition of selenide containing samples (\%)

\begin{tabular}{|c|c|c|c|c|c|c|c|c|c|c|}
\hline Condition & $\begin{array}{l}\text { Element } \\
\text { Group }\end{array}$ & $\mathrm{C}$ & $\mathrm{Si}$ & $\mathrm{Mn}$ & $\mathrm{Cr}$ & Mo & $\mathrm{Se}$ & $\mathrm{Al}$ & $\mathrm{S}$ & $\mathrm{O}$ \\
\hline \multirow{2}{*}{ Air melting } & $A_{\mathrm{Se}^{-1}}$ & $\begin{array}{c}(0.11) \\
0.08\end{array}$ & $\begin{array}{c}(0.40) \\
0.19\end{array}$ & $\begin{array}{c}(0.65) \\
0.54\end{array}$ & $\begin{array}{c}(10.0) \\
9.5\end{array}$ & $\begin{array}{c}(0.3) \\
0.30\end{array}$ & $\begin{array}{c}(0.3) \\
0.49\end{array}$ & $\begin{array}{l}(0.02) \\
0.023\end{array}$ & 0.052 & 0.015 \\
\hline & $A_{\mathrm{Se}^{-2}}$ & $(0.13)$ & $(0.40)$ & $(0.43)$ & $(10.8)$ & $\begin{array}{r}(3.0) \\
2.90\end{array}$ & $\left(\begin{array}{l}(, 29) \\
0.29\end{array}\right.$ & $\begin{array}{l}(,,)^{\prime} \\
0.016\end{array}$ & 0.041 & - \\
\hline \multirow{2}{*}{ Vacuum melting } & $V_{\mathrm{Se}_{\mathrm{e}}^{-1}}^{\circ}$ & $(0.08)$ & $\begin{array}{c}(0.35) \\
0.40\end{array}$ & $\begin{array}{c}(0.50) \\
0.43\end{array}$ & $(10,25)$ & $\begin{array}{c}(0.3) \\
0.31\end{array}$ & $(0,19)$ & - & 0.028 & 0.004 \\
\hline & $V_{\mathrm{Se}^{-2}}^{\circ}$ & $(0.05)$ & $\begin{array}{c}(0.35) \\
0.42\end{array}$ & $(0,42)$ & $\begin{array}{l}(,, 0) \\
10.08\end{array}$ & $\begin{array}{l}(3.0) \\
3.02\end{array}$ & $(0.34)$ & - & 0.039 & - \\
\hline
\end{tabular}

Note: $(\quad)=$ Aimed composition. 


\section{Microstructure Tests of Nonmetallic Inclusions in Steels}

Longitudinal section of the microspecimen extracted from middle part of ingot was observed microscopically. $(\times 400,1,000)$. In this test, difference in size between precipitating particles on the surface and ones in central part was considerable in accordance with the cooling velocity during solidification. Results obtained in the test of sample $A-2$ is shown in Fig. 2. Therefore, the part about $25 \mathrm{~mm}$ distant from the surface was chosen for observation in this case.

At first, the distribution of sulphide inclusions in the group added $0.3 \%$ Mo were shown in Photo 1 . In $A$-group, the distribution of sulphide inclusions was considerably observed not only on grain boundary but also in grain, and these sulphide inclusions consisted of light grey colour ( $\mathrm{MnS}$ ) and pale orange colour
(Cr-sulphide) $)^{3)}$. In these sulphide inclusions hercynite $\left(\mathrm{FeO}, \mathrm{Al}_{2} \mathrm{O}_{3}\right)$ was often observed as nuclei. One of the microphotographs obtained in this group

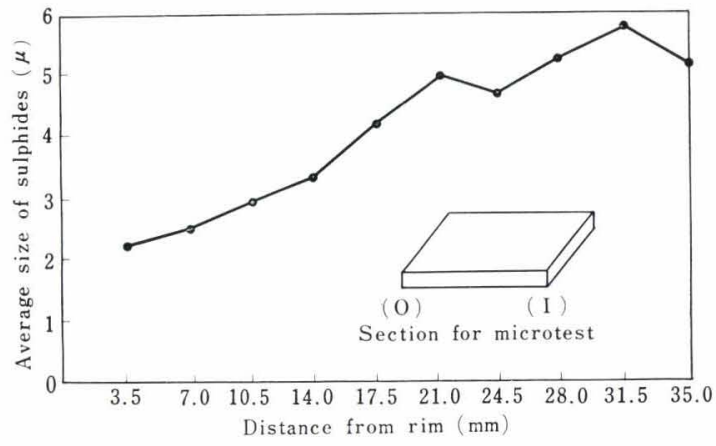

Fig. 2. Size distribution of sulphide in $A-2$ sample

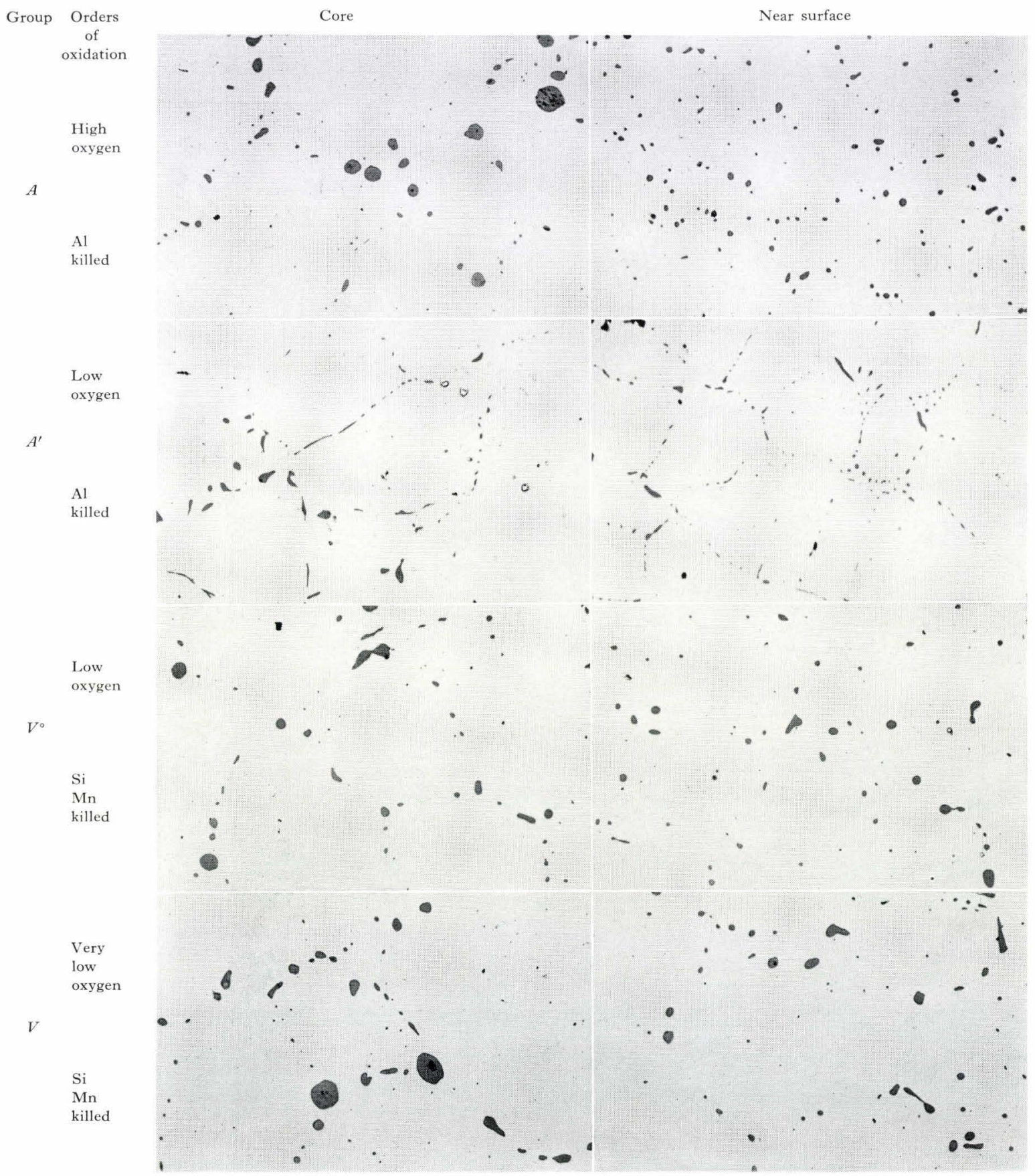

Photo 1. Microphotographs of distribution of sulphide inclusions in each group ( $\times 500$ non-etch) 
was shown in Photo 2(a).

In $A^{\prime}$-group the sulphide inclusions were precipitated mostly in eutectic form, of which inclusion consisted of a single phase of light grey colour, and no hercynite was found there.

The sulphide inclusions in $V^{\circ}$-group were deposited mainly on grain boundary, and in comparison with those in $A$ - and $A^{\prime}$-groups, they had very fine particles of a light grey colour phase.

As compared with $V^{\circ}$, group had the large tendency of precipitation on grain boundary, and there were two kinds of particles, i.e., comparatively large ones and fine ones, the former of which were partly with two phases as in $A$-group. One example is shown in Photo 2(b). Sample containing 3\%Mo had the same tendency as $0.3 \%$ base materials. The form of inclusions occurred in samples with 10\% Mo was similar to the materials above, but the colour was quite different and the respective groups formed the single phase of light grey colour with tint of orange. The colour of this inclusions were in close agreement with the mixed coloured ones mentioned above which consisted of two phases.

In $A-4$ samples added $\mathrm{Zr}$, the constitution and distribution of inclusions were nearly the same as those of $A-1$ sample but it contains $\mathrm{ZrN}$, and it was not easily deformed by forging. A black coloured phase of trapezoid form was frequently found in these sulphide inclusions.

Microstructures of Se-added $A_{\mathrm{Se}}, V_{\mathrm{Se}}^{\circ}$-group were

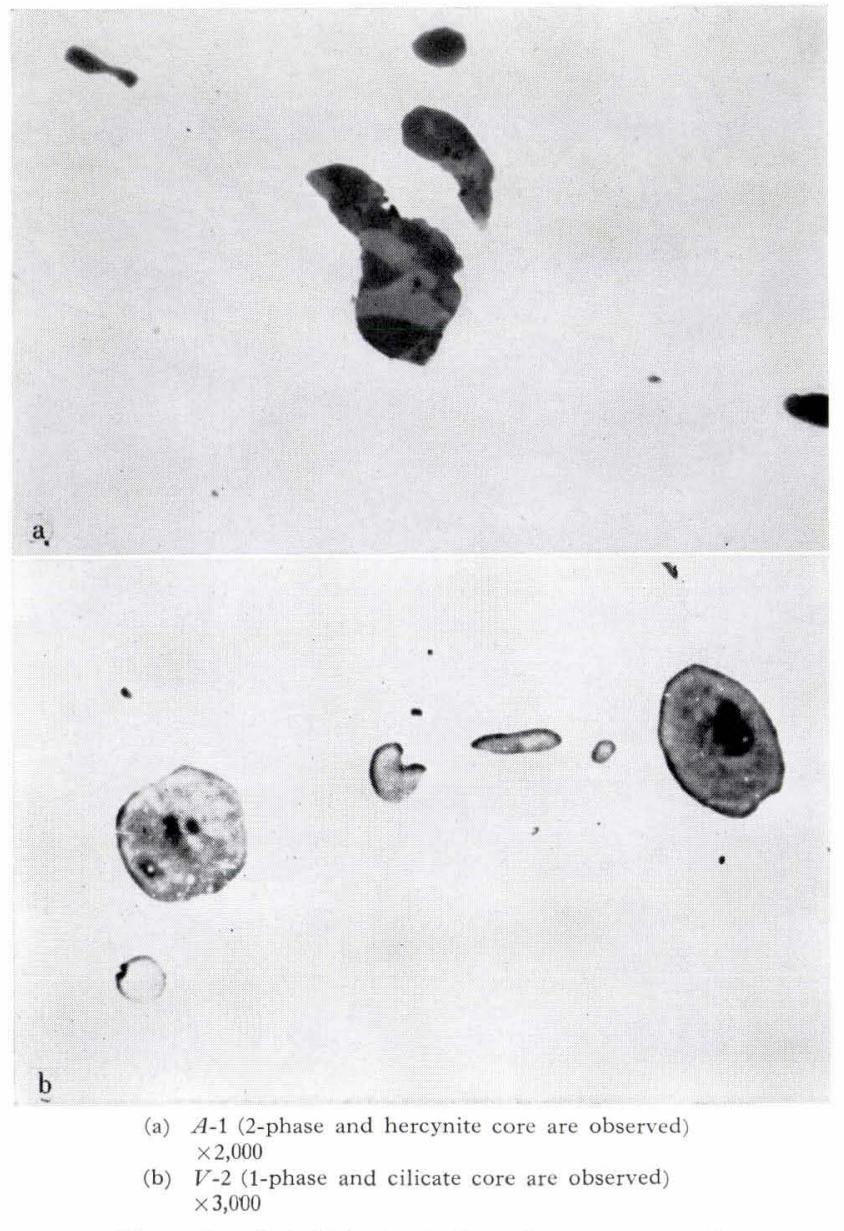

Photo 2. Sulphide inclusions in as cast steel shown in Photo 3. In sample of $0.3 \% \mathrm{Mo}$, a uniform dispersion of the selenide inclusions of very fine and granular particles was observed but in the case of $3 \%$ Mo relatively large particles were found. In samples of $A_{\mathrm{Se}}$-group, a kind of fine eutectic structure of selenides and oxides was observed, and in places there were also hercynites as nuclei for forming inclusions.

On the other hand in $V_{\mathrm{Se}}^{\circ}$-group, despite some amount of silicated, selenides were of one phase and fine eutectic structure was not observed. Microstructure of $A_{\mathrm{Se}}$ - samples was shown in Photo 4(b).

The quantitative examination of deforming of inclusions was performed by the forging samples. Results were shown in Fig. 3. The size of sulphides is plotted horizontally, which is represented by average of the longitudinal and the transverse length in cast state, and extended length in forging material; the frequency $(\%)$ is plotted vertically. In $A^{\prime}$-1-group the plasticity of elongated sulphides was relatively small and sulphides after forging were fractured into small size. Especially fine particles in inclusions of $2 \mu$ order in size increased in case of forging ratio: 16 . Such phenomena were not observed in $V^{\circ}-1, V-1-$ group but were rather similar to the case of $A$-1-group.

Then measurement of plasticity of the sulphides was done. The plasticity of inclusions in forging materials in comparison with matrix was given by a following equation:

where, $A_{1} / A_{2}$ : forging ratio

$$
P=\frac{b^{\prime} / a^{\prime}}{\left(A_{1} / A_{2}\right)^{3 / 2}}
$$

$a^{\prime}$ : minimum diameter of inclusion

$b^{\prime}$ : maximum diameter of inclusion

Each inclusion was regarded as an ellipsoid.

Summarizing the results of plasticity in each group at forging ratio: 16 and microphotograph of sulphides, Table 5 was obtained.

Thus, it could be known that the plasticity of sulphides in $A$-group was larger than that of $A^{\prime}$ - and $V^{\circ}$ group had smaller plasticity than in $V$-group.

In $A$-, $A_{\mathrm{Se}}$-group hercynites were observed as nuclei in inclusions, which were not deformed by forging. In $V$-, $V^{\circ}$ - and $V_{\mathrm{Se}}^{\circ}$-group, on the other hand, nuclei in inclusions were made of silicates and it was observed that these inclusions were elongated in associate with sulphides by forging. The typical photographs of these groups were shown in Photo 4(a).

The selenides had so small plasticity that even those of forging ratio: 16 could not be elongated into thread type.

The Identification of Inclusions by X-Ray Microanalyser

By using the same X-ray microanalyser as was used in the preceding experiment, Fe, Mn, $\mathrm{Cr}$ and Mo were identified on $A-4, A^{\prime}-1, V^{\circ}-3, V-1, A_{\mathrm{Se}}-1$ and $V V_{\mathrm{Se}^{\circ}}^{\circ}$ samples.

Measured values of samples in $A$-, $A^{\prime}$-groups varied greatly with the position. Average value was $\mathrm{Mn}: \mathrm{Cr}=$ $1: 1 \sim 1: 2.3$, and in $V$-, $V^{\circ}$-groups, $\mathrm{Mn}: \mathrm{Cr}=1: 1 \sim 1: 3$. In most samples a small amount of Mo was detected. Fe-contents differed in considerable grade for each sample and showed no definite tendency. From the 


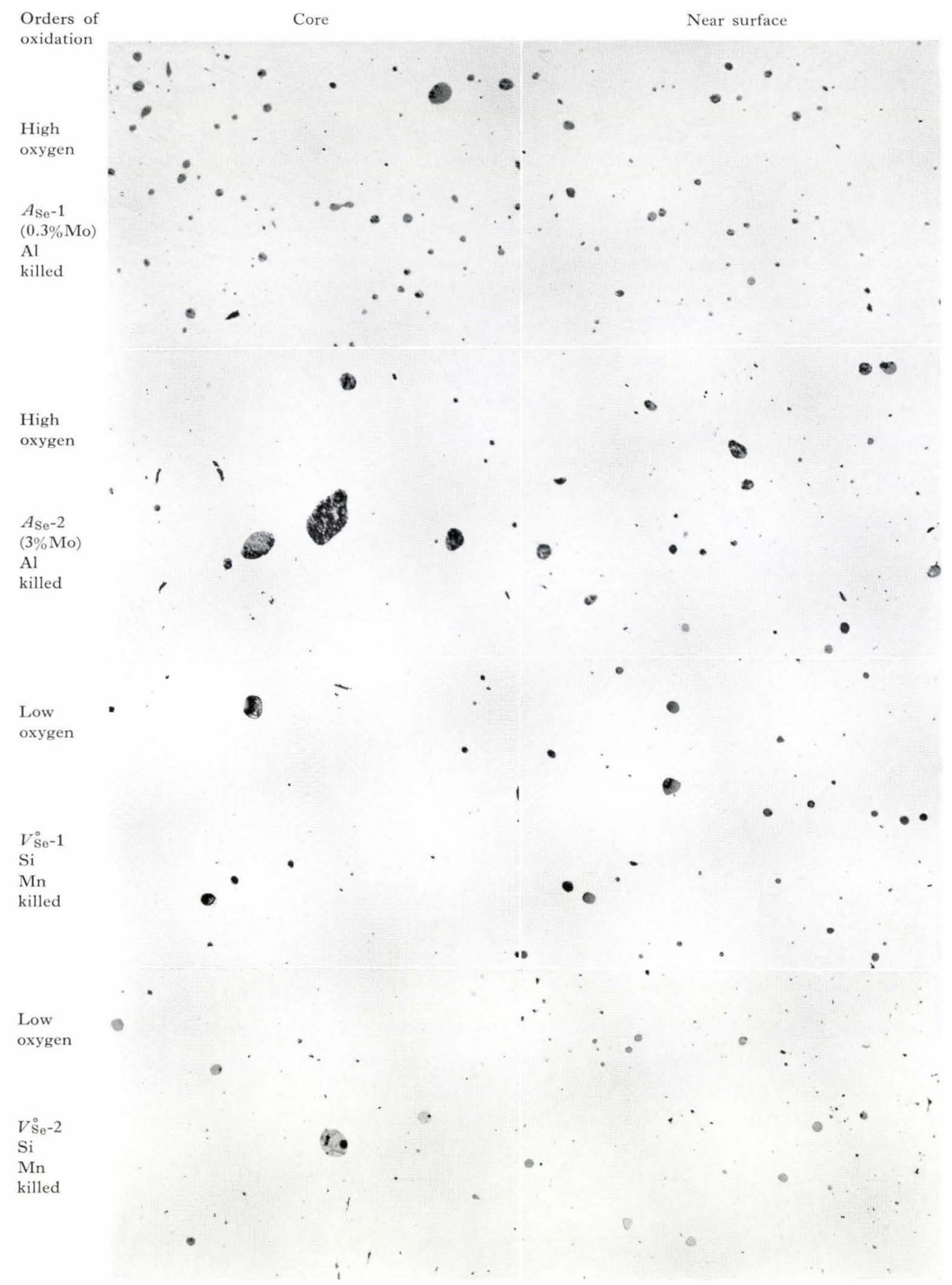

Photo 3. Microphotographs of distribution of selenide inclusions in each sample ( $\times 500$ non-etch)

results above, it was considered that the subject of the inclusions consisted of $\mathrm{MnS}$ and $\mathrm{Cr}$-sulphide.

The data of $A-1, V^{\circ}-3$ samples obtained by scanning survey of X-ray microanalyser were shown in Fig. 4 (Fe, Mn, Cr, Mo).

In $A-1$ sample remarkable variations of contents of chromium and manganese were observed and manganese was lessened in accordance with increase of chromium amount. The existence of sulphides of two phases found in the examination of the preceding microstructure well explains these phenomena. In $V^{\circ}-3$ sample such a tendency was not observed but it was known that the amount of manganese and chromium increase to the same degree. This result is in close agreement with that obtained in the preceding micro-examination: two phases were taken for one phase resulting from formation of solid solution or intermediate phase. Despite this sample contained $10 \% \mathrm{Mo}$, the concentration of molybdenum in inclusion more than matrix was not found in this sample.

Similar examination on the selenium added samples, named $A_{\mathrm{Se}^{-}}-1$ and $V_{\mathrm{Se}}^{\circ}-1$, showed that the concentrating trend of manganese into inclusions was remarkable. The ratio of $\mathrm{Mn}$ to $\mathrm{Cr}$ was $1: 0.75 \sim 1: 0.6$ and the amount of Se in inclusion was about one half and considerable concentration of aluminium and silicon was observed in it. From these results, though the existence of selenides of $\mathrm{Mn}$ and $\mathrm{Cr}$ was expected, possibility of formation of Mo-selenide was considered to be very little.

The Identification of Inclusions with X-Ray Diffraction Method of Electrolytic Residue 

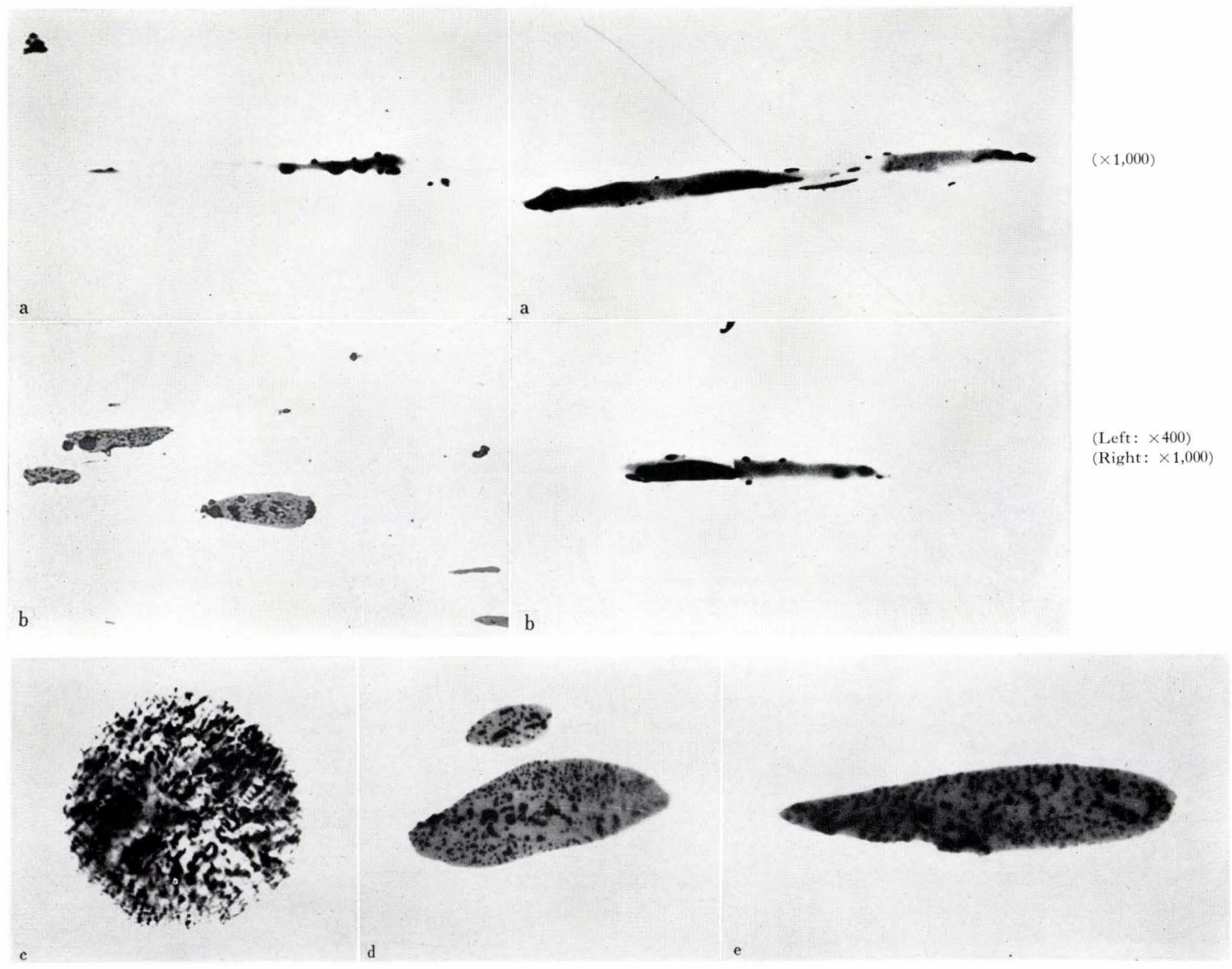

(a) Sulphide inclusions in $A-1$ and $V-1$ after forging (f.r. 4)

(b) Selenide inclusions in $A_{\mathrm{Se}}-1$ and $V_{\mathrm{Se}}^{\circ}-1$ after forging (f.r. 4)

(c) As cast $(\times 3,000)$ (d) After forging (f.r. 4$)(\times 3,000)$ (e) After forging (f.r. 16) $(\times 3,000)$

Photo 4. Microphotographs of sulphide and selenide inclusions
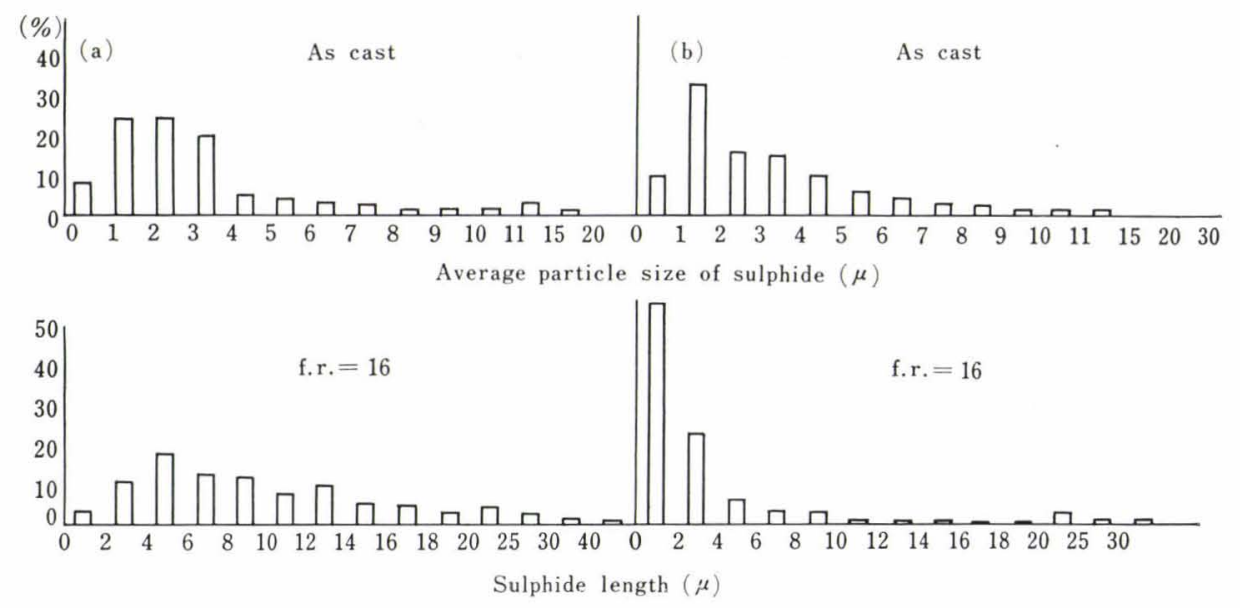

Fig. 3 .

(a) Sulphide size distribution in $A-1$ sample

(b) Sulphide size distribution in $A^{\prime}-1$ sample

The electrolysis of each sample was performed by using sodium citrate solution method. The X-ray diffraction of its residue was done under similar condition in the preceding experiment. The electrolysis conditions were as follows:

Electrolytic solution: $0.5 \mathrm{~N} \mathrm{HCl}+5 \% \mathrm{Na}$-Citrate

$+1 \% \mathrm{KBr}$

Current density: $\quad 20 \sim 30 \mathrm{~mA} / \mathrm{cm}^{2}$

Electrolysis time: $\quad 10 \sim 20 \mathrm{hr}$
The extracted residue was about $0.3 \sim 3 \%$ in each sample and contained some matrix, which caused the difficulty in X-ray diffraction. To make less the effect, magnetic separation method was applied. Results obtained on sulphur added samples was illustrated in Figs. 5 and 6.

In samples added $0.3 \%$ Mo a remarkable difference was found from group to group. In $A$-group the pattern lines accorded with the diffraction lines of $\alpha$ - 
Table 5. Results obtained from microscopic examination in sulphide inclusion

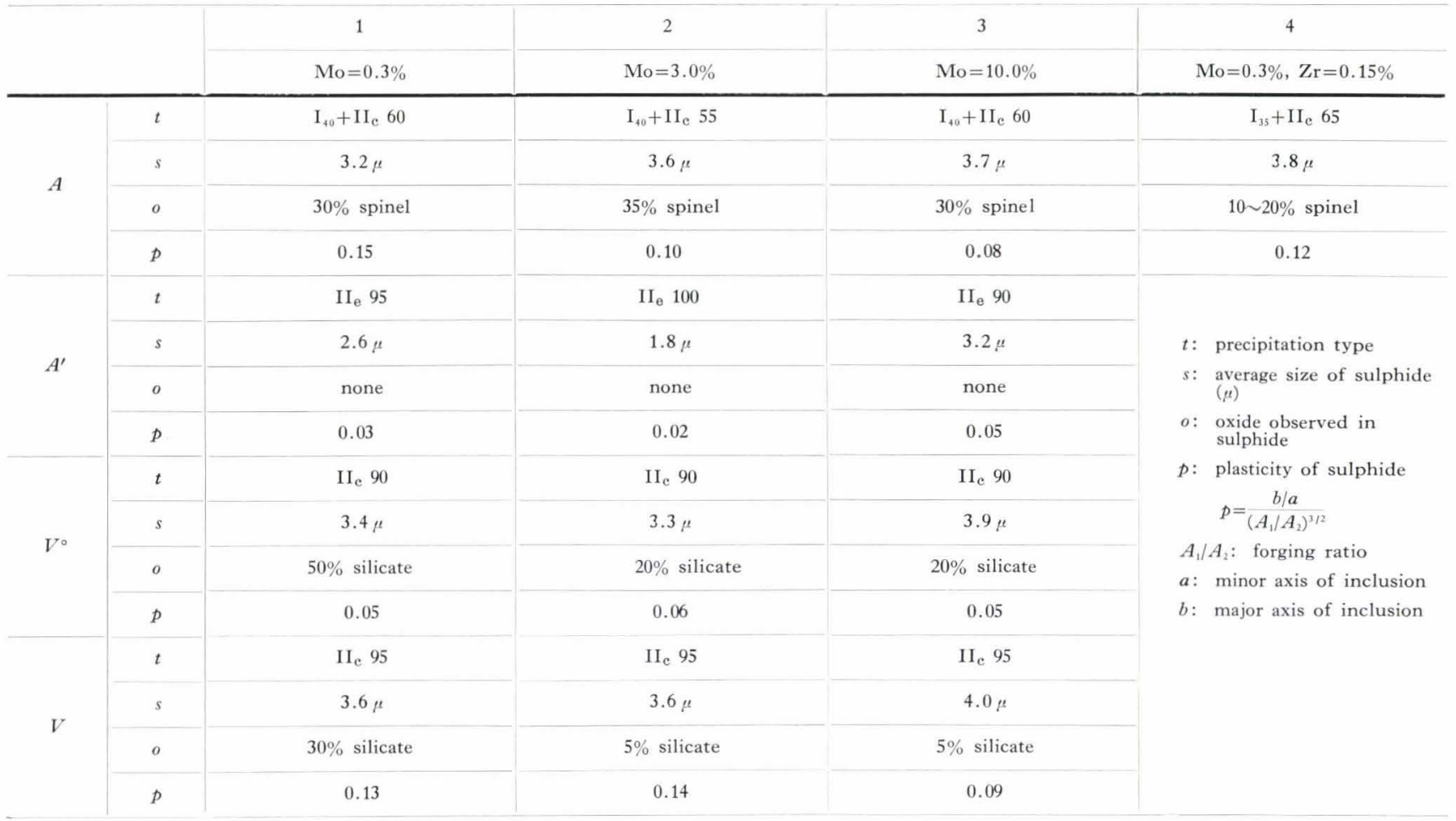
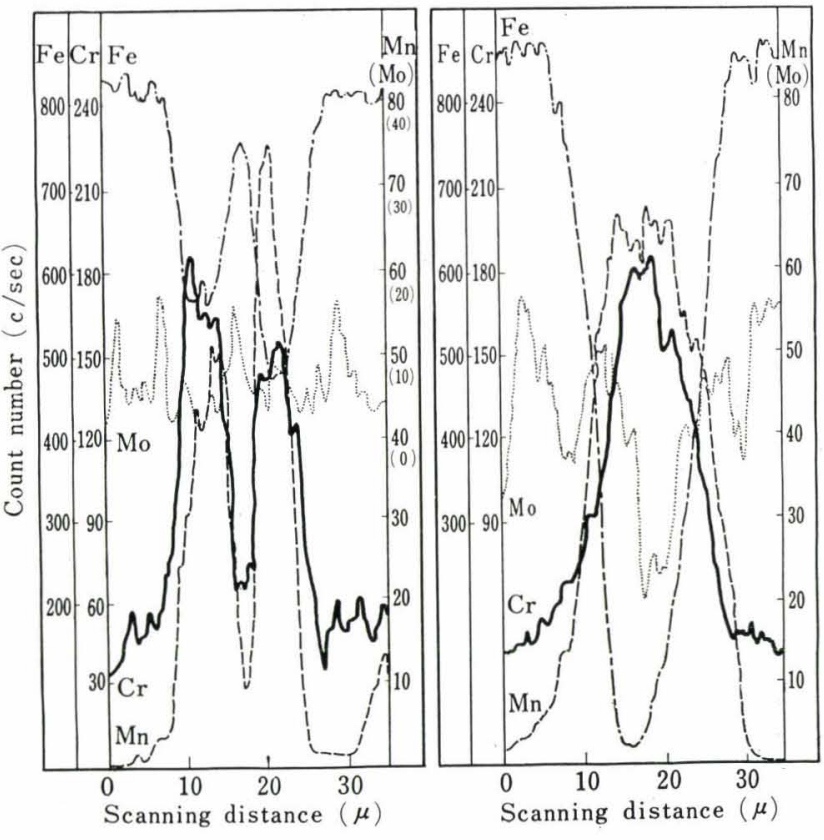

(a) $A-1(0.3 \% \mathrm{Mo})$

(b) $V^{\circ}-3(10 \% \mathrm{Mo})$

Fig. 4. Count number against scanning distance obtained by X-ray microanalyser in $A-1(0.3 \% \mathrm{Mo})$ and $V^{\circ}-3(10 \% \mathrm{Mo})$

$\mathrm{MnS}, \mathrm{Cr}_{2} \mathrm{~S}_{3}$ and $\mathrm{Cr}_{23} \mathrm{C}_{6}$ were observed, therefore the formation of these two types of sulphides can be recognized. In $A^{\prime}$-group, however, only $\alpha$-MnS was found and no $\mathrm{Cr}_{2} \mathrm{~S}_{3}$ and $\mathrm{Cr}_{23} \mathrm{C}_{6}$. This result agreed qualititatively with that of microscopic examination mentioned in the preceding section. The existence of two phases, one is light grey colour and the other pale orange, in sulphides of $A$-group was reported; the former had $\alpha$-MnS structure (NaCl type, $a=$

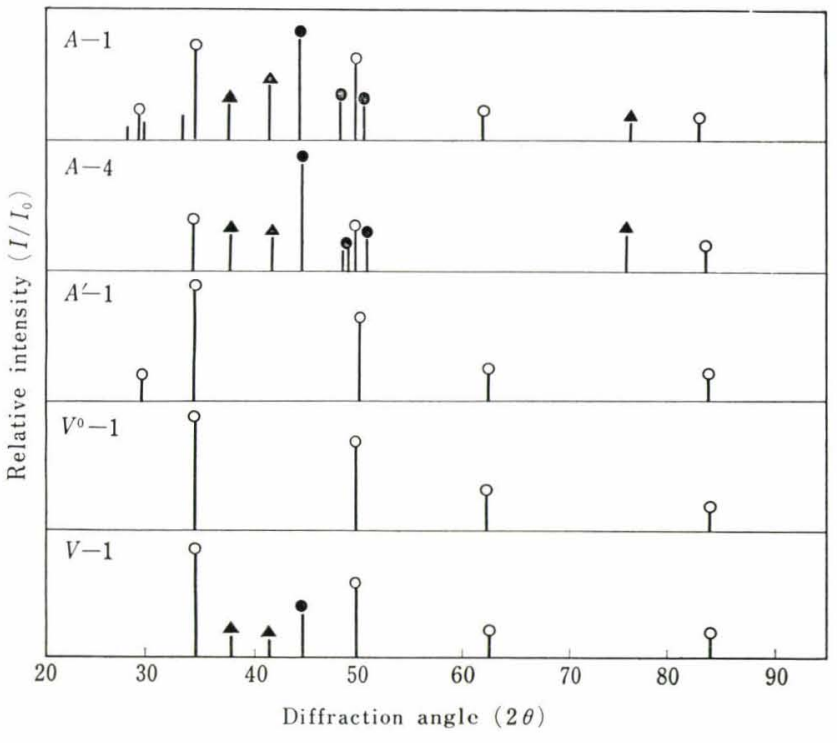

Fig. 5. Relative intensity against diffraction angle obtained from electrolytic residue $(0.3 \%$ Mo base sample)

$\circ-\mathrm{MnS} \bullet \mathrm{Cr}_{2} \mathrm{~S}_{3} \quad \mathrm{Cr}_{23} \mathrm{C}_{6}$

$5.22 \AA$ ) with dissolved $\mathrm{Fe}, \mathrm{Cr}$, and the latter had $\mathrm{Cr}_{2} \mathrm{~S}_{3}$-like structure (hexagonal type, $a=5.94 \AA$, $c=16.6 \AA)$ with dissolved $\mathrm{Mn}$. In $A^{\prime}$-group, $\alpha$-MnS was all what was observed, although about the same amount of $\mathrm{Cr}$ content was detected as in $A$-group. This phenomenon was ascribed to that the ratio of dissolved in inclusions to $\mathrm{MnS}$ was several tens percent. Although the two phases of $\alpha-\mathrm{MnS}$ and $\mathrm{Cr}_{2} \mathrm{~S}_{3}$ was detected in $V$-group, the amount of $\mathrm{Cr}_{2} \mathrm{~S}_{3}$ formation in them was relatively small comparing with $A$ group. A-4-group added $\mathrm{Zr}$ and $A$-1-group share alike tendency. It is supposed that this phenomenon 

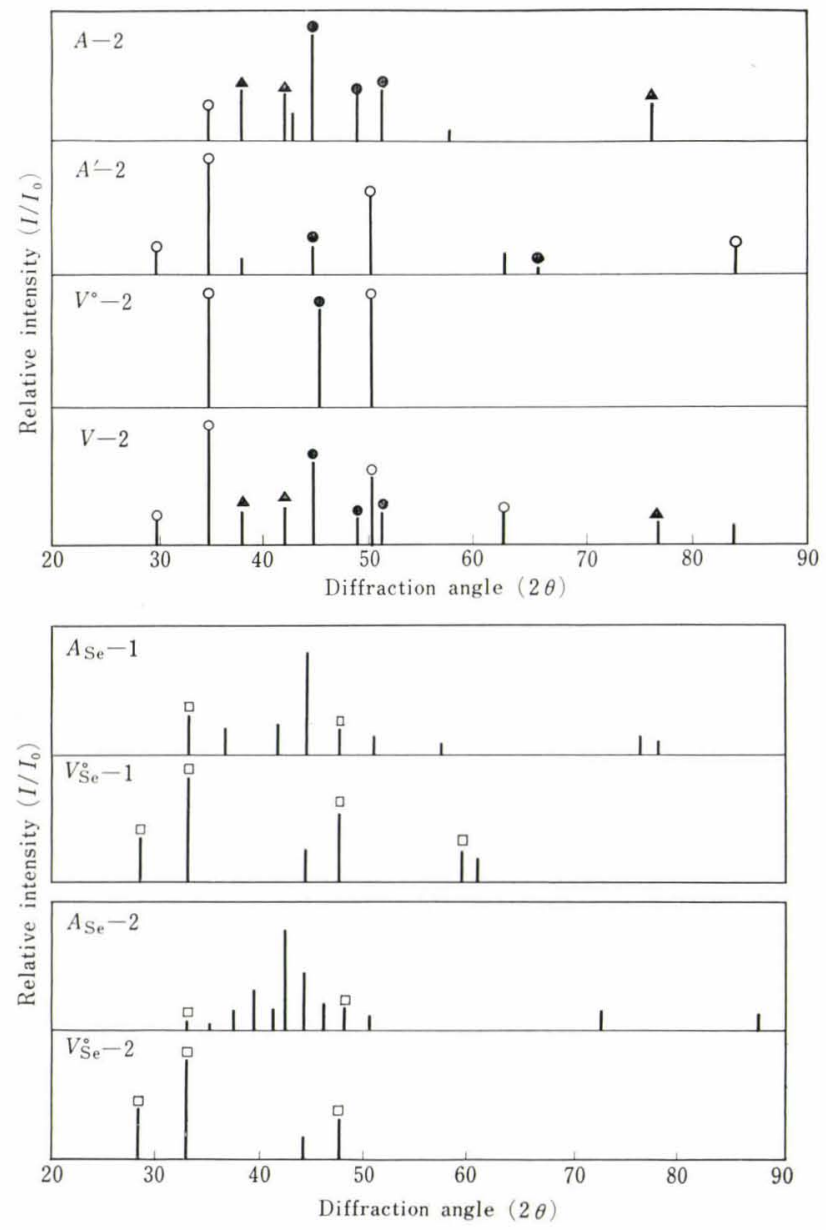

Fig. 6. Relative intensity against diffraction angle obtained from electrolytic residue. (Above: $3 \%$ Mo base, below: 0.3 and $3 \%$ Mo base.)

$\alpha$-MnS $\square \mathrm{Cr}_{2} \mathrm{~S}_{3} \quad \boldsymbol{A} \mathrm{Cr}_{23} \mathrm{C}_{6}$

was due to small quantity of zirconium added and that the oxidizing condition of molten steel was little improved because of preferred reaction with nitrogen.

In the base material containing $3 \% \mathrm{Mo}$, the increasing tendency of $\mathrm{Cr}_{2} \mathrm{~S}_{3}$ formation was recognized but alike tendency for $0.3 \% \mathrm{Mo}$ was applied to all group of this case.

Samples containing 10\% Mo had much difference in diffraction lines from samples above. Regarding the structure, it was all what was known that the crystal represented hexagonal type with extremely large axis ratio. The data of X-ray microanalyser proved that chromium and manganese were the principal ingredients and suggested the formation of a phase of a hexagonal type, $\mathrm{Cr}_{x}(\mathrm{Mn})_{y} \mathrm{~S}_{z}$.

The results of X-ray diffraction in $A_{\mathrm{Se}^{-}}, V_{\mathrm{Se}}^{\circ}$-group with Se were shown in Fig. 6. The crystal type of precipitation in selenides as well as in sulphides was changed by addition of molybdenum, and this effect had already been observed in the case of $0.3 \%$ Mo. In $A_{\mathrm{Se}^{-}}-1,2$ - and $V_{\mathrm{Se}}^{\circ}-1,2$-group, $\alpha$-MnSe $(\mathrm{NaCl}$ type, $a=5.46 \AA$ ) in precipitated phases was found, and the difference between Al-killed and MnSi deoxidized samples was greater than in the case of sulphides. In the course of examination with micro- analyser, $\mathrm{Cr},(\mathrm{Al})$ and $(\mathrm{Si})$ were found in the selenides. On the basis of these data, it was suggested that the dissolving proportion of oxide, i.e. $\mathrm{SiO}_{2}, \mathrm{Al}_{2} \mathrm{O}_{3}$ and $\mathrm{Cr}_{2} \mathrm{O}_{3}$, in addition to dissolving $\mathrm{Cr}$ in $\alpha-\mathrm{MnSe}$, was eminently larger than in the sulphides. All diffraction line except $\alpha-\mathrm{MnSe}$ could not be recognized.

\section{Discussion}

\section{Sulphur Containing Samples}

It is shown in Table 3 that carbon contents of airmelted steels are higher than those of steels vacuummelted (Mn-Si deoxidation), because carbon added reacts as a deoxidizer in vacuum. The yield of sulphur in vacuum melting is also a little lower and sulphur contents of $V^{\circ}$-group enriched with oxygen are the low value of $0.2 \%$.

As for the distribution of sulphides, the tendency to precipitate along primary grain boundaries increases with the order $A, V^{\circ}, V$ (Table 5). This can be interpreted by the occurring status of oxides as follows: in sulphides and matrices of samples of $A$-group exist a number of oxides of spinel type $\mathrm{FeO}((\mathrm{Al}$ $\left.\mathrm{Cr})_{2} \mathrm{O}_{3}\right)$, because of the heavy oxidation of the steel bath at melting down, although this steel was later deoxidized by aluminium. On the other hand, most oxides in $V$ - and $V^{\circ}$-group consist of silicate $(\mathrm{MnO}$. $\mathrm{SiO}_{2}$ ) containing a little $\mathrm{Al}_{2} \mathrm{O}_{3}$.

In $A$-group, oxides of spinel type, which are already present before $\alpha$-iron begins to solidify, behave as nuclei for the sulphide formation, so that the sulphides occur almost in primary crystals. Most sulphides in $V^{\circ}$ - and $V$-groups precipitate in chain like way along primary grain boundaries, because deoxidized product, silicate, precipitates at so low temperature, after $\delta$-iron solidifies mostly, that the silicate does not behave as nuclei.

A little difference between the distribution of sulphides in $V^{\circ}$ - and $V$-group could be attributed to the difference of sulphur and oxygen concentrations in the melts. Sulphides in $A^{\prime}$-group precipitate in eutectic manner with matrix. This is because in $A^{\prime}$-group pure and fine particles of $\mathrm{Al}_{2} \mathrm{O}_{3}$ were formed as deoxidation products, but no oxides of spinel type because of slight oxidation of the melts. This fine particle of $\mathrm{Al}_{2} \mathrm{O}_{3}$, which is scarcely wettable with the melt around itself, has no nucleation power and in this case there are few other oxides acting as nuclei. Sulphides, therefore, precipitate in eutectics after the melt is supercooled to the eutectic region of Fe-Mn-S system. Generally, sulphides which precipitate during solidification of steel are influenced by the nucleation effects of oxides, and so the distribution of sulphides can be considered to show the supercooled state.

It is observed in $0.3 \%$ Mo steel of only $A$-group that sulphides consist of two phases identified as $\alpha-\mathrm{MnS}$ and $\mathrm{Cr}_{2} \mathrm{~S}_{3}$ by $\mathrm{X}$-ray diffraction of the isolated residue and EPMA, though most sulphides in $A^{\prime}$-, $V$ - and $V^{\circ}$ groups consist of one phase. The formation of two phases structure is probably due to the variations of oxygen and carbon amounts in the molten steel of $A$ - 
group. As for 3\% Mo containing steels, this phenomenon is also observed and the amount of $\mathrm{Cr}_{x} \mathrm{~S}_{y}$ phase increases as a whole. In 10\% Mo steels a intermediate phase between $\alpha-\mathrm{MnS}$ and $\mathrm{Cr}_{2} \mathrm{~S}_{3}$ are observed and its pattern of X-ray diffraction differs from the both others. It follows from these facts above that in low carbon $\mathrm{Cr}$-steels elements of carbon, oxygen and molybdenum promote the reaction: $2 \underline{\mathrm{Cr}}+3 \underline{\mathrm{S}}$ $=\mathrm{Cr}_{2} \mathrm{~S}_{3}$, which is caused by the progress of the reaction: $\underline{\mathrm{Mn}}+\underline{\mathrm{S}}=\mathrm{MnS}$. Molybdenum in 10\% Mo steel seems to increase the formation of $\mathrm{Cr}_{2} \mathrm{~S}_{3}$ so markedly that a intermediate phase $\mathrm{Cr}_{x}(\mathrm{Mn})_{y} \mathrm{~S}_{z}$ or a solid solution appears as a result.

It has been already reported that oxygen in steel decreases the plasticity of sulphides ${ }^{1)}$. Table 5 shows that the relative plasticity of sulphide in $10 \%$ Mo steels is lower than in low Mo steels, which is based on the fact that sulphides in 10\% Mo steels consist of only one phase which is rich in chromium and forms a solid solution containing some molybdenum, while sulphides in lower Mo steels consist of two phases.

Sulphides in $V^{\circ}$-group enriched with a little oxygen have a comparatively low plasticity as shown in Table 5. On the other hand, fine particles of eutectic sulphides in $A^{\prime}$-group which have low oxygen content are not deformed by hot work. This low plasticity of fine particles could be attributed to low value of shearing stress on the small sulphide and to the fact that $\alpha-\mathrm{MnS}$ contains considerable amount of chromium as a solid solution as described above.

Free energies of $\mathrm{FeS}, \mathrm{MnS}, \mathrm{MoS}_{2}$ and $\mathrm{Mo}_{2} \mathrm{~S}_{3}$ at $1,500^{\circ} \mathrm{C}$, at which the Cr-steels concerned solidify, are $17.7,40.4,17.1$ and $51.2 \mathrm{kcal} / \mathrm{mol}^{10)}$ respectively. One third of the free energy of formation of $\mathrm{Mo}_{2} \mathrm{~S}_{3}$ is $17 \mathrm{kcal}$ and roughly equal to the value of $\mathrm{FeS}$, which means that $\mathrm{Mo}_{2} \mathrm{~S}_{3}$ may precipitate alike FeS. But $\mathrm{Mo}_{2} \mathrm{~S}_{3}$ was not found in this experiment. The free energy of formation of chromium sulphide is presumed to be higher than that of $\left(\mathrm{Mo}_{2} \mathrm{~S}_{3}\right)$, though it is not actually determined yet. Further thermodynamical considerations shall need data of dissolution and interface energy.

Except that inclusions of $\mathrm{Zr}$-added $A$-4 sample often contain a trapezoid of black phase, they are not so different from those of other $A$ samples without zirconium for the reasons that zirconium concentration of $A-4$ sample is so low as $0.15 \%$, considerable part of which exists as oxide or nitride. So only a small part included in the steel forms $\mathrm{ZrS}$, hence the solidification mechanism of $A-4$ sample is considered to be influenced little by zirconium but predominantly by carbon, nitrogen and oxygen in the molten steel.

\section{Selenium Containing Samples}

The effect of molybdenum in selenium containing steels is larger than that in sulphur containing steel; a phase of $\mathrm{Cr}_{x}(\mathrm{Mn})_{y} \mathrm{Se}_{z}$ is observed even in $3 \%$ Mo steel. The solubility of oxide in selenide is larger than in sulphide and selenide forms a eutectic structure with oxide in the inclusions. In $\mathrm{Mn}-\mathrm{Si}$ deoxidized steels, such eutectics is not observed but inclusions are mainly of $\alpha$-MnSe.

\section{Summary}

The effects of oxygen and deoxidation condition and also molybdenum on the formation of sulphide or selenide in resulphurized low carbon steel were investigated.

The effects of some elements in samples based on $0.1 \% \mathrm{C}, 0.4 \sim 0.6 \% \mathrm{Mn}$ and $0.25 \sim 0.4 \% \mathrm{~S}$ steel was as follows:

(1) With increasing sulphur content large FeS inclusions coalesced and floated up. They precipitated generally in globule as $\mathrm{MnS}$ inclusions and scarcely along primary grain boundaries, while increased carbon content had marked effect to form film like FeS network along grain boundaries.

(2) Increase of molybdenum content up to $2 \%$ made the $\mathrm{FeS}$ phase change into $\mathrm{MnS}$ in grain, though thickened concentration of molybdenum was not observed in the sulphides consisting mainly of $\alpha-\mathrm{MnS}$.

Sulphides and selenides in the high chromium steels were identified and investigated morphologically. The results are as follows:

(1) The distribution and forms of sulphides in these steels were notably affected by the deoxidizing conditions before solidified. Those phenomena can presumably be interpreted in the relation between the natures of deoxidation products and the nucleation of sulphide, e.g. wetting properties.

(2) Sulphides in low carbon high chromium steel containing $0.3 \%$ Mo are made up of a solid solution of $\alpha-\mathrm{MnS}$ with much chromium or consist of two phases of $\alpha-\mathrm{MnS}$ and $\mathrm{Cr}_{2} \mathrm{~S}_{3}$. Their precipitation is affected by carbon and oxygen contents in the steel.

(3) Molybdenum forms no sulphide by itself in this experiment and does not seem to be concentrated in the sulphides, while it gives the precipitation of $\alpha$ $\mathrm{MnS}$ and $\mathrm{Cr}_{2} \mathrm{~S}_{3}$ a change to increase the $\mathrm{Cr}_{2} \mathrm{~S}_{3}$ phase. The particular sulphide is formed in 10\% Mo steel and its plasticity is notably lower than the others.

(4) Fine particles of eutectic sulphides in Al-killed steel are little deformed at hot work; this could also be ascribed to the fact that $\alpha-\mathrm{MnS}$ contains much chromium as a solid solution.

(5) The addition of $0.15 \% \mathrm{Zr}$ has no remarkable effects on the composition and precipitation of sulphide in this experiment.

(6) Selenium, which is similar to sulphur, forms MnSe containing chromium in the steel used. MnSe inclusions have lower plasticity than sulphides and they are not deformed into strings at hot work. The effect of molybdenum on selenide was roughly the same as that on sulphide.

\section{REFERENCES}

1) L. v. Vlack: Trans. Met. Soc., Amer. Inst. Min., Met. छ Pet. Eng., 45 (1953), 741-757.

2) F.W. Boulger: A.S.T.M. Research Report Paper, May (1958), 80.

3) Nishizawa, Kaneko \& Tamaki: J. Japan Inst. of Metals, 25 (1961), 328-331.

4) Nishizawa, Kaneko \& Tamaki : J. Japan Inst. of Metals, 25 (1961), 560-564.

5) R. Vogel et ali.: Arch. Eisenhüttenw. 6 (1933), 495-500; 
11 (1937), 41-54; 12 (1938), 261-267; 11 (1938), 457-462 ; 15 (1942), 413-418, 551-565; 33 (1961), 879-882.

6) Kaneko, Nishizawa \& Tamaki : J. Japan Inst. of Metals, 27 (1963), 312-318.

7) Kaneko, Nishizawa \& Tamaki : J. Japan Inst. of Metals,
27 (1963), 299-304.

8) Kaneko, Nishizawa \& Tamaki: J. Japan Inst. of Metals, 24 (1960), 837-841.

9) A.I.S.I. Standard.

10) J. Elliott: Thermochemistry for Steelmaking, 1 (1960). 